\title{
Endoplasmic reticulum stress serves an important role in cardiac ischemia/reperfusion injury (Review)
}

\author{
YONGXUE RUAN ${ }^{1}$, JINGJING ZENG ${ }^{1}$, QIKE JIN ${ }^{1}$, MAOPING CHU ${ }^{1}$, \\ KANGTING JI ${ }^{1}$, ZHONGYU WANG ${ }^{2}$ and LEI LI $^{1}$ \\ ${ }^{1}$ Institute of Cardiovascular Development and Translational Medicine, \\ The Second Affiliated Hospital and Yuying Children's Hospital of Wenzhou Medical University, \\ Wenzhou, Zhejiang 325027; ${ }^{2}$ Wenzhou Medical University, Wenzhou, Zhejiang 325035, P.R. China
}

Received March 3, 2020; Accepted August 19, 2020

DOI: $10.3892 /$ etm.2020.9398

\begin{abstract}
Although acute myocardial infarction is one of the most common fatal diseases worldwide, the understanding of its underlying pathogenesis continues to develop. Myocardial ischemia/reperfusion (I/R) can restore myocardial oxygen and nutrient supply. However, a large number of studies have demonstrated that recovery of blood perfusion after acute ischemia causes reperfusion injury to the heart. With progress made in the understanding of the underlying mechanisms of myocardial I/R and oxidative stress, a novel area of research that merits greater study has been identified, that of I/R-induced endoplasmic reticulum (ER) stress (ERS). Cardiac I/R can alter the function of the ER, leading to the accumulation of unfolded/misfolded proteins. The resulting ERS then induces the activation of signal transduction pathways, which in turn contribute to the development of I/R injury. The mechanism of I/R injury, and the causal relationship between I/R and ERS are reviewed in the present article.
\end{abstract}

\section{Contents}

1. Introduction

2. Mechanisms of $I / R$ injury

3. Pathways of ERS

4. I/R as an activator of the ERS

5. ERS in turn mediates $I / R$ damage

6. Conclusion and future perspective

Correspondence to: Professor Lei Li, Institute of Cardiovascular Development and Translational Medicine, The Second Affiliated Hospital and Yuying Children's Hospital of Wenzhou Medical University, 109 Xueyuanxi Road, Wenzhou, Zhejiang 325027, P.R. China

E-mail: 1ileiii@hotmail.com

Key words: myocardial ischemia/reperfusion injury, endoplasmic reticulum stress

\section{Introduction}

Myocardial infarction (MI) is one of the leading causes of mortality worldwide and occurs due to the acute occlusion of the coronary arteries (1). Although revascularization treatment has conferred proven efficacy for patients with MI, it also causes undesired ischemia/reperfusion (I/R) injury following the restoration of epicardial blood flow $(2,3)$. I/R injury is defined as tissue injury that occurs when the blood supply to organs is interrupted and then returns (4). To the frustration of interventional cardiologists and other health professionals, the desire of whom is the fast restoration of blood flow to the heart muscle, successful therapeutic strategies that can prevent I/R injury in the clinic have yet to be established (5).

The endoplasmic reticulum (ER) is an important organelle for eukaryotic cell survival and development $(6,7)$. It is responsible for the biosynthesis, folding, assembly and modification of most secreted and transmembrane proteins. Furthermore, it serves a role in cellular lipid and steroid synthesis (8). Approximately $33 \%$ of cellular protein production and folding occurs in the ER (9). Excessive protein synthesis, beyond the capacity of the folding mechanism in cells, or excess accumulation of unfolded $/ \mathrm{misfolded}$ proteins in the ER lumen will disrupt ER homeostasis and trigger the unfolded protein response (UPR), eventually leading to ER stress (ERS) (10). Events in the process of I/R can alter ER function and consequently influence the accumulation of unfolded $/ \mathrm{misfolded}$ proteins. The resulting ERS then induces the activation of three signal transduction pathways, including the protein kinase R-like endoplasmic reticulum kinase (PERK)-eukaryotic translation initiation factor 2A (eIF2a)-activating transcription factor (ATF) 4-C/EBP homologous protein (CHOP) pathway, pro-ATF6-ATF6-CHOP pathway and inositol requiring enzyme 1 (IRE1)-X-box binding protein 1 (XBP1) pathway, which in turn promote the development of I/R injury (11).

The aim of the present review was to summarize current understanding of the multifactorial mechanisms that contribute to the genesis of I/R injury, and the relationship between I/R and ERS. In addition, possible future targets of therapeutic interventions to enhance recovery after $I / R$ were discussed. 


\section{Mechanisms of I/R injury}

Calcium $\left(\mathrm{Ca}^{2+}\right)$ overload. $\mathrm{Ca}^{2+}$ overload is a complex process that serves a fundamental role in $\mathrm{I} / \mathrm{R}$ damage. During ischemia, anaerobic metabolism dominates, which causes a reduction in intracellular $\mathrm{pH}$. To buffer the resulting accumulation of hydrogen ions, the sodium ion exchanger discharges excessive hydrogen ions, resulting in a sodium ion influx (12). Simultaneously, ischemia also depletes ATP, which inactivates ATPases such as the $\mathrm{Na}^{+} / \mathrm{K}^{+}$ATPase and reduces the efflux of $\mathrm{Ca}^{2+}$ whilst restricting the re-uptake of $\mathrm{Ca}^{2+}$ into the ER, causing $\mathrm{Ca}^{2+}$ overload (13). Opening of the mitochondrial permeability transition pore (MPTP) also occurs with the aforementioned physiological changes in the cell, leading to the dissipation of mitochondrial membrane potential and further impairments to ATP production (14). $\mathrm{Ca}^{2+}$ reuptake into the ER/sarcoplasmic reticulum (SR) via the SR/ER Ca ${ }^{2+}$ ATPase (SERCA) is damaged by $\mathrm{I} / \mathrm{R}$, whereas $\mathrm{Ca}^{2+}$ release through the ryanodine receptor is enhanced, both of which potentiate an increase in $\mathrm{Ca}^{2+}$ levels in the cytosol (15). The ryanodine receptor is a $\mathrm{Ca}^{2+}$ channel that is located on the ER/SR network. It rapidly releases $\mathrm{Ca}^{2+}$ from the ER/SR network and exerts a wide range of physiological functions, such as functioning in myocardial cell excitation and $\mathrm{Ca}^{2+-}$ dependent acceleration of ATP production, which serve an important role in maintaining the intracellular $\mathrm{Ca}^{2+}$ balance $(15,16)$.

$\mathrm{Ca}^{2+}$ overload can damage cardiac function. Rapid accumulation of $\mathrm{Ca}^{2+}$ in cardiomyocytes after reperfusion can induce dynamic uncoupling, increase electrical conduction dispersion, and facilitate re-entry formation and arrhythmias. In addition, it can induce early or late depolarization contact, ventricular tachycardia or even ventricular fibrillation with short syndromic intervals $(17,18) . \mathrm{Ca}^{2+}$ overload also promotes the damage or death of cardiomyocytes during reperfusion in multiple ways. The opening of the MPTP results in a large number of hydrogen ions entering the mitochondrial matrix from the mitochondrial intermembrane space, leading to the dissipation of the transmembrane potential gradient and obstruction of the electron transport chain. Water can also simultaneously enter the matrix down an osmotic gradient, causing mitochondrial edema, rupture or disintegration, which may lead to cell necrosis (19). Upon myocardial I/R, SERCA accelerates $\mathrm{Ca}^{2+}$ uptake and renders the cytoplasmic SR cycle in a state of high load, which leads to $\mathrm{Ca}^{2+}$ oscillation and affects the expression of $\mathrm{Ca}^{2+}$ in cells (20). Intracellular $\mathrm{Ca}^{2+}$ overload can result in excessive myocardial fiber contraction, which not only damages the cells themselves, but can also cause metabolic disorders or damage the structure of adjacent cells by mechanical forces such as traction (21). Increases in intracellular $\mathrm{Ca}^{2+}$ during myocardial ischemia can promote calpain translocation, but low intracellular $\mathrm{pH}$ in ischemia prevents it from being activated. During blood flow reperfusion, with the recovery of intracellular $\mathrm{pH}$, calpain can be activated (22). The calpain family of cysteine proteases is activated by the elevation of $\mathrm{Ca}^{2+}$. Excessive calpain degrades a multitude of intracellular proteins in the cytoskeleton, ER and mitochondria, in turn causing damage to cells or organelles (23).

Accumulation of reactive oxygen species (ROS). ROS are a group of unstable, active molecules, including superoxide $\left(\mathrm{O}_{2}^{-}\right)$, hydrogen peroxide $\left(\mathrm{H}_{2} \mathrm{O}_{2}\right)$ and hydroxyl radicals, which were first described as free radicals in skeletal muscle (24). ROS are generally considered to be toxic byproducts of aerobic respiration and are the major cause of macromolecular damage (25). ROS are produced by organelles and enzymes, including: i) Mitochondria, where oxygen functions as the terminal electron acceptor of the electron transport chain; ii) the ER, where $\mathrm{H}_{2} \mathrm{O}_{2}$ is produced as a by-product of protein folding; iii) peroxisomes, where enzymes that produce $\mathrm{H}_{2} \mathrm{O}_{2}$, such as polyamine oxidase, are localized; and iv) NADPH oxidase (NOX), a membrane bound enzyme complex that has a role in killing intracellular pathogens (26). Function of these organelles and enzymes will be affected following exposure to environmental cues, including chemotherapeutic drugs, ionizing radiation and environmental damage (27). $\mathrm{O}_{2}^{-}$is a single electron reduction product of oxygen that exists in large quantities in the human body that can mediate cellular damage. $\mathrm{O}_{2}^{-}$is produced by complexes I and III of the mitochondrial electron transfer chain, where oxygen is reduced by electron leakage. Additionally, the plasma membrane NOX (NADPH oxidases), a family of flavoenzymes, which catalyzes the oxidation of NADPH, can generate $\mathrm{O}_{2}^{-}(28,29) . \mathrm{O}_{2}{ }^{-}$is eliminated by superoxide dismutases (SODs) 1 and 2, and is then rapidly converted into $\mathrm{H}_{2} \mathrm{O}_{2}$ with low toxicity (30). A disruption of the homeostasis between ROS and endogenous antioxidant production results in oxidative stress (31), which leads to cellular dysfunction, DNA damage, lipid peroxidation and apoptosis induction (32). In addition, oxidative stress affects the normal function of a wide range intracellular signaling pathways and promotes the pathological development of cardiovascular diseases (33).

During cardiac ischemia, myocardial cells are in a state of hypoxia, where mitochondrial electron transfer chain complexes are significantly reduced and SOD anions are produced (34). During reperfusion, ROS levels are increased significantly due to the reduction in electron leakage and mitochondrial detoxification (34), causing oxidative stress. Free radical explosion and oxidative stress are important mechanisms of myocardial I/R injury. Mitochondrial electron transfer chain complex $\mathrm{I}$ is inactivated during myocardial ischemia because of the highly reductive environment with low $\mathrm{PO}_{2}$ and low ADP (35). After reperfusion, the impaired activity of complex I can also lead to ROS-induced damage to the mitochondrial phospholipids and respiratory chain super complex, potentiating the electron leakage of complex I further. This process promotes a vicious cycle of oxidative stress that ultimately leads to mitochondrial dysfunction (36). Under these conditions, excessive mitochondrial ROS cause oxidative damage to proteins, lipids and DNA, as well as excitation-contraction uncoupling, arrhythmia, cardiac hypertrophy, apoptosis, necrosis and fibrosis (37). However, low levels of ROS attenuate myocardial I/R injury through ischemic preconditioning. Recent evidence has suggested that short-term intermittent hypoxia (IH), similar to ischemic preconditioning, can serve a cardioprotective role (38). A previous study demonstrated that IH increased mitochondrial tolerance to $\mathrm{Ca}^{2+}$ overload and delayed MPTP opening induced by oxidative stress (39). In addition, a previous study has shown that IH may increase the expression of SOD and glutathione peroxidase (40). 
Inflammatory cytokines and apoptotic factors. Long-term ischemia can lead to irreversible cellular necrosis, which triggers the release of a variety of pro-inflammatory mediators, including cytokines and growth factors, leading to inflammatory cell infiltration (41). During late stage I/R, genes associated with inflammation are activated to produce mediators, including IL-1, IL-6, TNF- $\alpha$ IFN-regulating factor and $\mathrm{NF}-\kappa \mathrm{B}$, all of which promote neutrophil adhesion and transmembrane migration, leukocyte infiltration, and cytokine and chemokine release, eventually leading to cell death. I/R can activate the inflammation cascade to cause further tissue damage (42). TNF- $\alpha$ participates in the development of myocardial injury during I/R injury, during which its expression level is increased, promoting adhesion and interaction between leukocytes and endothelial cells (43). This increases the infiltration of granulocytes into the $\mathrm{I} / \mathrm{R}$ region to mediate myocardial cell damage (43). IL-1 is secreted by activated monocytes and macrophages, and its expression is also significantly increased during I/R. Intercellular adhesion molecule 1 (ICAM-1) participates in the adhesion of leukocytes to vascular endothelial cells and induces cytotoxicity by adhering to cardiomyocytes (44). Enhanced ICAM-1 binding can feed back to endothelial cells and macrophages to promote the expression of inflammatory mediators or cytokines (44). During I/R, the release of inflammatory cytokines and chemokines leads to the activation of neutrophils and macrophages, which promotes tissue damage (45). Neutrophil infiltration serves an important role in myocardial I/R injury. This step is initiated by the binding of vascular endothelial adhesion molecules with corresponding ligands on neutrophils to mediate the adhesion of neutrophils to endothelial cells. Mast cells serve an important role in stimulating the inflammatory response by releasing regulators that can trigger the cascade of cytokine release (46). Cyclic inflammatory markers, including C-reactive protein, IL-6 and IL-1, are associated with increased infarct size and poor prognosis. In recent years, pro-inflammatory cells such as monocytes and macrophages have been documented to be a potential cause of MI using a number of cell tracking and molecular imaging techniques (47).

During I/R, different gene families can also serve distinct roles in apoptosis. Apoptosis is a tightly controlled process that is conserved among species and involves the Bcl-2 and caspase families of proteins in addition to oncogenes, such as c-Myc and p53 (48). The activation, upregulation, translocation and integration of precursor $\mathrm{Bcl}-2$ proteins, including $\mathrm{Bax}, \mathrm{BH} 3$ interacting-domain death agonist, p53 upregulated modulator of apoptosis (PUMA) and Bcl-2 interacting protein 3 (BNIP3), into the mitochondrial membrane within ischemic injury tissues has been previously reported $(49,50)$. In addition, pro-apoptotic and anti-apoptotic $\mathrm{Bcl}-2$ proteins have been found to regulate $\mathrm{Ca}^{2+}$ homeostasis, which is an important mechanism of I/R injury (51). The caspase family also serves a key role in I/R-induced cell death. Pan-cysteine aspartase inhibitors, including zVAD-FMK and MX1013, can attenuate apoptosis and cell death induced by I/R $(52,53)$. However, it has been previously reported that caspase inhibition may instead drive the cell towards necrotic death (54). A number of studies have demonstrated that the overexpression of BNIP3 in HL-1 myocardial cells can activate Bax to promote the opening of the MPTP and increase cell death in response to I/R injury $(55,56)$.
Changes in microRNAs (miRNAs/miRs). miRNAs are short, single-stranded non-coding RNAs that are 21-23 nucleotides in length and regulate gene expression by inhibiting translation or promoting the degradation of RNA (57). Mature miRNAs are processed from primary miRNA, which is cleaved by a microprocessor complex that consists of the RNase-III endonuclease Drosha, RNA-binding protein DiGeorge syndrome critical region gene 8 and other cofactors, to produce 70-100 nucleotide hairpin precursor small RNAs. Following export to the cytoplasm by the nuclear export protein exportin-5, they are trimmed by the RNase III ribonuclease dicer to produce a mature miRNA duplex that is $\sim 21$ nucleotides in length (58).

Several studies have demonstrated that miRNA function is closely associated with cardiovascular disease, and a number of non-cardiac miRNAs are reported to be biomarkers of myocardial injury and predictors of clinical outcomes after acute MI. miR-633b and miR-1291 have been documented to indicate MI with high specificity and sensitivity (59), whereas miR-150 and miR-486 expression levels could be used to distinguish between patients with and without ST-elevation MI (60). A previous study revealed that heart biopsies from patients with heart failure demonstrated a significant increase in miR-377 expression compared with that in normal control hearts (61). In a mouse cardiac I/R model, human CD34 ${ }^{+}$ cells in immune-deficient mice were silenced following the intra-myocardial transplantation of miR-377, which promoted neovascularization and reduced interstitial fibrosis 28 days after I/R induction to improve left ventricular function (61).

MiRNAs serve significant roles in cardiac I/R injury and function by a wide range of different mechanisms. A previous study demonstrated that miR-1 and miR-133 mediated opposite effects when regulating myocyte survival in I/R models, where miR-1 was pro-apoptotic and miR-133 was anti-apoptotic (62). This difference may be due to their respective downstream targets. Increased miR-1 expression resulted in the downregulation of several anti-apoptotic genes, including heat shock protein (hsp)60, hsp70, insulin-like growth factor-1 and Bcl-2, whereas miR-133 negatively regulated the expression of pro-apoptotic genes, such as caspase-9 and caspase-3 (62-64). Another study revealed that miR-133 overexpression reduced cardiac fibrosis after transverse aortic banding compared with that in normal controls, implicating the cardioprotective effects of miR-133a on I/R-triggered cardiac remodeling (65). miR-21 has been demonstrated to protect cardiomyocytes from I/R injury by targeting several apoptotic genes, including phosphatase and tensin homolog, cell death 4 and Fas ligand (66-68). Furthermore, miR-21 has been reported to inhibit the proliferation, migration and tubulogenesis of endothelial cells, and promote the survival of cardiomyocytes and cardiac fibroblasts after myocardial I/R (69). miR-25 and miR-145 can reduce mitochondrial ROS stress and $\mathrm{Ca}^{2+}$ overload by inhibiting the expression of mitochondrial $\mathrm{Ca}^{2+}$ uniporter and $\mathrm{Ca}^{2+} /$ calmodulin-dependent protein kinase II (CaMKII) (70). miR-214 may protect cardiomyocytes from oxidative damage induced by ROS formation initiated by $\mathrm{Ca}^{2+}$ overload by inhibiting sodium/ $/ \mathrm{Ca}^{2+}$ exchanger 1 (71-73).

From the aforementioned studies, it can be concluded that miRNAs regulate the expression of pro-apoptotic/antiapoptotic genes to regulate cardiac fibrosis, inflammation, ROS generation and $\mathrm{Ca}^{2+}$ homeostasis. A number of studies have 
demonstrated that various miRNAs, including miR-21 (67), miR-144/451 (74), miR-192 (75) and miR-199a (76), are associated with ischemic preconditioning. Additionally, some experimental studies have revealed that inhibition of miR-15 and miR-92a in pig models of acute myocardial I/R, especially at the beginning of reperfusion, can reduce the size of the MI $(77,78)$. This suggests that miRNA treatment may be a feasible therapeutic approach (75).

\section{Pathways of ERS}

ERS is an evolutionarily conserved cell stress response that is associated with numerous diseases, including cardiovascular, Alzheimer's and Parkinson's diseases, and diabetes, renal failure, osteosarcoma and pancreatic ductal adenocarcinoma (79-85). Under physiological conditions, the ER is an important organelle that serves a key role in cellular processes, including protein folding, assembly, modification and secretion, lipid synthesis and $\mathrm{Ca}^{2+}$ storage. However, when the ER is exposed to stress stimuli, such as ROS exposure and $\mathrm{Ca}^{2+}$ overload, homeostasis is impaired, which results in the accumulation of unfolded/misfolded proteins (86). These changes may eventually lead to ER dysfunction, collectively known as ERS (86).

Several ER transmembrane sensors are expressed to detect the accumulation of unfolded proteins, including PERK, ATF6 and IRE1, which activate the signal pathways of (eIF2 $\alpha$-ATF4 -DNA-damage-inducible transcript/CHOP, pro-ATF6-cleaved ATF6-CHOP, and IRE1-spliced (Xbp1), respectively (79). This upregulates the expression of ER chaperones and ER-related degradation components (6). The UPR can activate the ER chaperone glucose-regulated protein 78 (GRP78) following isolation by any of the three ER sensors (PERK, ATF6 and IRE1). In the absence of ERS, binding to GRP78 results in the inactivation of these sensors. GRP78 is released from the sensors, where they can interact with misfolded and unfolded proteins when ERS occurs. Ultimately, the UPR is triggered by the transcription of genes encoding proteins involved in this process, leading to a reduction in global protein synthesis (87). The ultimate purpose of the UPR is to restore normal ER function, the failure of which results in apoptosis $(88,89)$. The three main ERS pathways are described in the following sections.

PERK-eIF2a-ATF4-CHOP pathway. A previous study indicated that the PERK signaling pathway serves an essential role in preventing the abnormal accumulation of unfolded proteins in the ER to promote cell survival (90). PERK is a type I transmembrane ER protein that has a ligand-independent dimerization domain at the $\mathrm{N}$-terminus, which is concealed by binding immunoglobulin protein (BIP)/GRP78 in the absence of ERS, and a serine/threonine protein kinase domain at the C-terminus without endonuclease activity (91). PERK can block the translation of most proteins, leaving only a specific few, such as ATF4 and CHOP, to be translated $(92,93)$. Translation of ATF4 activates the expression of CHOP by directly interacting with its 5'-untranslated region (92).

Activation of PERK leads to eIF $2 \alpha$ phosphorylation. In addition, it promotes caspase-12 and CHOP overexpression, which can direct ERS towards cell apoptosis (94). CHOP can in turn activate downstream targets during ERS, resulting in apoptotic cell death (95).

Pro-ATF6-ATF6-CHOP pathway. One arm of the UPR is the activation of the ER membrane protein ATF6, a fragment of which is translocated into the nucleus to activate the transcription of genes that mediate protein folding (96). ATF6 has two subtypes: ATF6 $\alpha$ and ATF6 $\beta$ (96). The accumulation of misfolded proteins causes ATF6 $\alpha$ to be transported to the Golgi apparatus $(97,98)$. There, it is sheared and the N-terminal fragment, p50-ATF6a, is transferred to the nucleus, where it regulates the transcription of genes associated with protein quality control, translocation, folding and degradation (99). ERS leads to the vesicular exit of ER ATF6, which is subsequently degraded by site-1 and site-2 proteases (S1P and S2P) in the Golgi complex. This cleavage cuts off the cytoplasmic domain of ATF6 from its transmembrane anchorage and intraluminal domain, following which the cytoplasmic ATF6 domain enters the nucleus to transcriptionally upregulate UPR target genes (100).

IRE1-XBRLP1 pathway. IRE1 is a type I transmembrane glycoprotein that can be divided into two categories: IRE1 $\alpha$ and IRE1 $\beta$. IRE1 $\alpha$ is widely expressed in different tissues, whereas IRE1 $\beta$ is only expressed in intestinal epithelial cells (101). IRE1 $\alpha$ senses the accumulation of unfolded proteins and is activated by dissociation with the ER chaperone GRP78/BIP (102-104). IRE1 then dimerizes and trans-autophosphorylates itself to activate its endonuclease domain under ERS. This endonuclease domain then acts on the Xbp1 gene and performs an unconventional splicing. After 26 nucleotides are removed, a spliced mRNA is produced, which increases the transcription of UPR target genes (105). Activation of the ER splicing factor IRE1 $\alpha$ and the splicing transcription factor Xbp1 can induce the transcription of chaperones, which are necessary for facilitating protein folding (105). A previous study reported that the activation of the PERK-eIF $2 \alpha$ and IRE1 $\alpha$-Xbp1 signaling pathways inhibited apoptosis and promoted proliferation without affecting ERK and AKT signaling activation (93). The UPR has been associated with a number of diseases, including cardiovascular, Alzheimer's and Parkinson's diseases, and IRE1 has been the focus of several drug discovery projects such as ligands that interact with IRE $\alpha$ 's kinase and pre-emptive activation of IRE1 $\alpha$ 's homeostatic mode $(79,80,106)$.

\section{I/R as an activator of the UPR}

The UPR is associated with numerous pathological processes, including cardiovascular disease, I/R injury, neurodegenerative diseases, diabetes mellitus, viral infection and cancer (107). Some of the earliest studies on the effects of I/R on the UPR were conducted in the brain $(81,108)$. A previous study has demonstrated that several pathways of the UPR are activated in the ischemic rabbit brain such as that of PERK-Xbp1-eIF2 $\alpha$, leading to translation arrest (108). Several studies have demonstrated that Xpb1, genetic markers of GRP78 and the UPR are activated in hypoxic cultured ventricular myocytes or HL-1 atrial myocytes from neonatal rats or adult mice (109-111). Therefore, ischemia and I/R can activate numerous components 
of the UPR in cardiomyocytes both in vivo and in vitro (112). In a neuronal studie ERS has been reported to be associated with neuronal cell death following ischemia (113). A study demonstrated that global cerebral I/R induced time-dependent differences in ER gene expression at both mRNA and protein levels, which was affected by pre-ischemic therapy (114).

Cardiomyocyte injury is induced by four pathophysiological events during I/R: $\mathrm{Ca}^{2+}$ overload, ROS accumulation, inflammatory cytokine release and apoptotic factor release. In addition, changes in the miRNA expression profile is another method by which $\mathrm{I} / \mathrm{R}$ can regulate the UPR, as described in an earlier part of this review. As described in the present review, oxidative stress serves an important role in the I/R process, as ROS can activate apoptosis and ERS at various stages. The FOXO family of transcription factors is involved in a number of biological processes, including the oxidative stress response, cell proliferation, apoptosis and metabolism (115). The most well-studied members of the FOXO family include FOXO1, FOXO3, FOXO4 and FOXO6 (115). A Previous study has demonstrated that FOXO4 serves an important role in ROS-induced apoptosis (116). Increased ROS production leads to acute renal ischemia by negatively interfering with the normal function of signaling pathways, inducing inflammatory infiltration and renal cell death (117). A study previously revealed that treatment with the bromodomain-containing protein 4 inhibitor, which exerts protective effects against renal I/R injury, suppressed I/R-induced apoptosis and ERS by activating PI3K/AKT signaling and blocking FOXO4-dependent ROS production (118). Blocking ROS using N-acetylcysteine has also been demonstrated to inhibit hypoxia/reoxygenationinduced apoptosis and ERS protein expression. The relationship between ROS and ERS-induced apoptosis has been confirmed, where ROS production can induce apoptotic cell death and ERS (118).

One previous study demonstrated that $\mathrm{H}_{2} \mathrm{~S}$ pretreatment and overexpression of miR-133a in the myocardium inhibited cardiomyocyte apoptosis and enhanced cell viability (119). In addition, concomitant miR-133a overexpression has been revealed to significantly increase cardiomyocyte proliferation, migration and invasion, in turn reversing I/R-induced ERS and cardiomyocyte apoptosis in vitro and in vivo. This suggests that miR-133a protects cardiomyocytes against I/R-induced ERS and subsequent apoptosis (119). A long non-coding RNA named urothelial carcinoma-associated 1 (UCA1), is only expressed in the heart (120). It has previously been reported that cardiac I/R triggers the expression of UCA1, and the production of ROS in cells and mitochondria to mediate apoptosis by oxidative stress and ERS. Overexpression of UCA1 can also protect $\mathrm{H} 9 \mathrm{C} 2$ cells from ERS and cell apoptosis induced by I/R (121). After co-treatment with TUDCA, a drug for clinical use that can protect cardiomyocytes from oxidative stress-induced injury (122), H9C2 cell injury induced by the effect of UCA1 siRNA was reversed (121). To summarize the activation function of $\mathrm{I} / \mathrm{R}$ to UPR, as described hereafter, a general scheme is presented in Fig. 1A.

\section{UPR in turn mediates $I / R$ damage}

The ER serves a pivotal role in cardiomyocytes, as the correct synthesis and folding of proteins in the ER is indispensable for the normal functioning of the heart (123). However, although ERS and the UPR have been extensively studied in non-muscle ER, there remains an insufficient number of studies on ERS and the UPR in the cardiovascular field (124).

If the UPR signal activation during the early stages of ERS is not sufficient in resolving stress, the persistent activation of proximal effectors (PRRK, ATF6 and IRE1) will result in the appearance of a distinct UPR-induced protein setup, where other signaling pathways are activated, all of which combine to promote cell death $(125,126)$. Notably, a previous study indicated that pre-activation of ATF6 in the hearts of transgenic mice conferred protective effects against I/R injury (127). In addition, a study indicated that the upregulation of GRP78 during ischemic preconditioning protected cultured cardiomyocytes from further ischemic damage (128). These studies suggested that when the UPR is activated in the heart during ischemia or $\mathrm{I} / \mathrm{R}$, it may exert protective effects against the stress response in myocardial cells. By contrast, several studies have demonstrated that UPR may lead to I/R injury of the heart. A previous study demonstrated that overexpression of the ERS response protein PUMA potentiated apoptosis in cultured cardiomyocytes via the UPR (129). Another study revealed that UPR activation promoted the activation of caspase-3, JNK and p53, which contributed to cardiomyocyte apoptosis (130). Additionally, in cultured cardiac myocytes, UPR mediated protective effects against ischemia activation in the early stages of ischemia, whereas the same response resulted in predominantly apoptotic characteristics in the latter stages (131). The distinct functions of the UPR may be dependent on the degree of ATF6, PERK and IRE-1 activation, and the nature of the ERS. ATF6 may mediate the activation of mostly protective proteins, whilst PERK may induce the activation of apoptotic genes (127). Therefore, brief ischemic stress may lead to changes in the proteome under the regulation of the UPR to promote protective effects, whereas prolonged ischemia may lead to changes in the proteome leading to cellular damage.

It has previously been reported that pathological ERS is relevant in a variety of physiological outcomes, including impaired $\mathrm{Ca}^{2+}$ homeostasis, increased apoptotic signaling, disrupted protein secretion and increased apoptotic signaling (132-134).

During ERS, CHOP has been demonstrated to induce the expression of ER oxidase 1, which activates inositol triphosphate receptor-mediated $\mathrm{Ca}^{2+}$ release into the cytosol and activates CaMKII to induce apoptosis (135-137). It has been revealed that Xbp1 and ATF6 may mediate the overexpression of GRP94, which could attenuate myocardial cell necrosis induced by $\mathrm{Ca}^{2+}$ overload or ischemia (138).

$\mathrm{Ca}^{2+}$ overload serves an important role in ERS-induced I/R injury. The $\mathrm{Ca}^{2+}$ dependence of cell death can be enhanced by a reduction in ATP. ATP concentration is decreased during ERS, which reduces the levels of intracellular $\mathrm{Ca}^{2+}$ stored in the ER (129). It has previously been reported that inhibiting calpain can improve ischemic myocardial injury and myocardial function in an experimental model of myocardial I/R (139-141).

The UPR can regulate a number of mitochondrial functions, including bioenergetics, membrane potential and the degree of cytochrome $c$ release (142). The UPR can also 


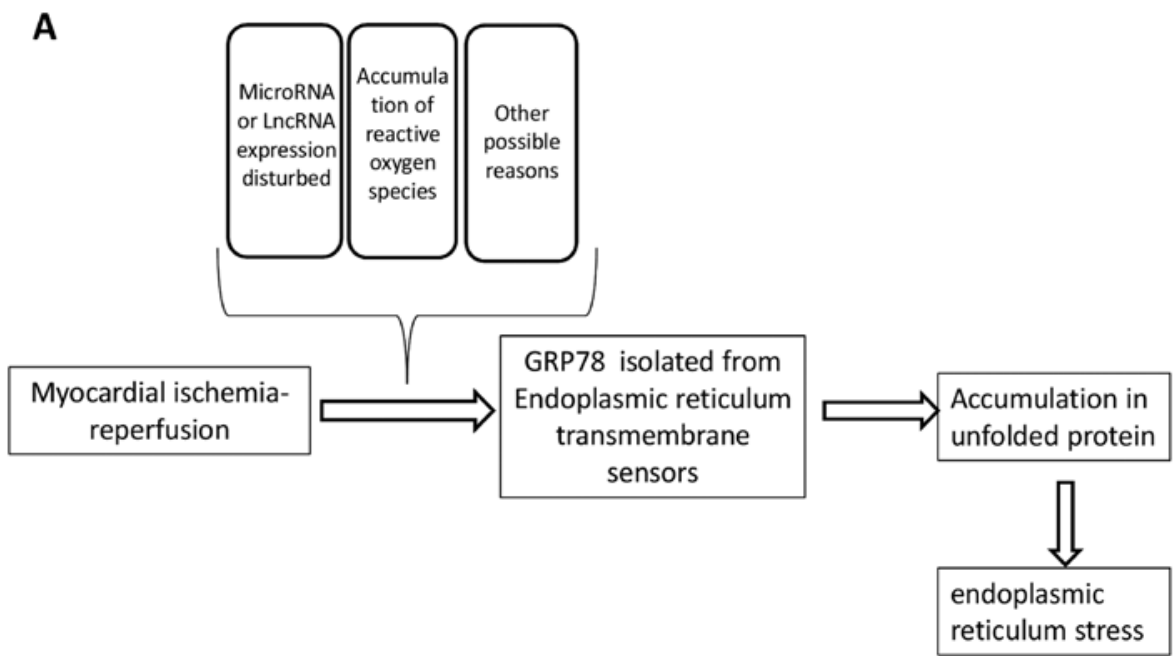

B

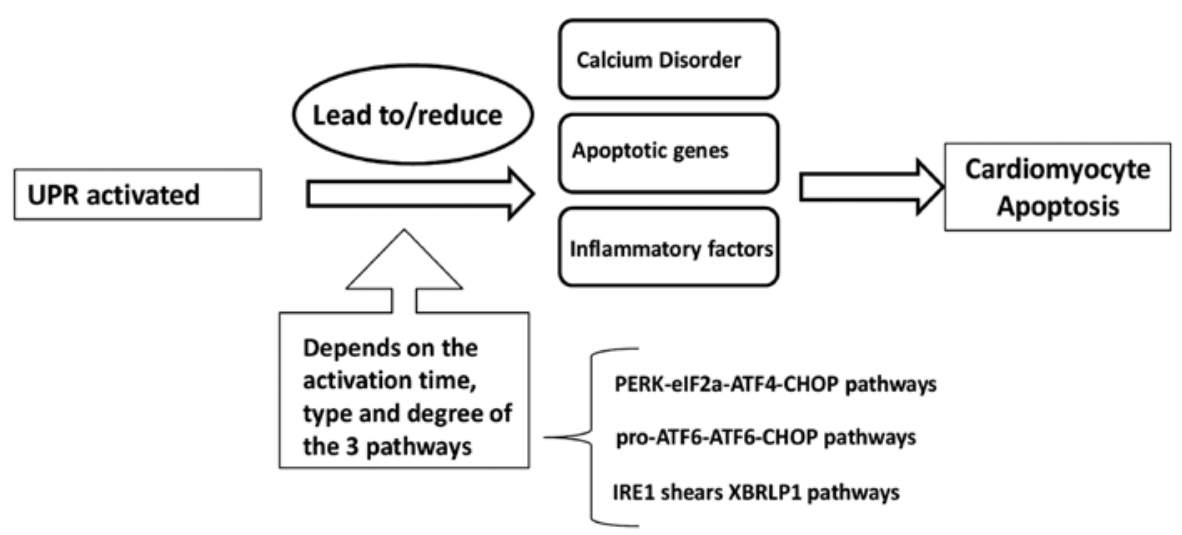

Figure 1. (A) I/R as an activator of the UPR. (B) UPR, in turn, affects I/R damage. I/R, ischemia/reperfusion; UPR, unfolded protein response; GRP78, glucose regulated protein 78; lncRNA, long non-coding RNA; PERK, protein kinase R-like endoplasmic reticulum kinase; eIF2a, eukaryotic translation initiation factor 2a; IRE, inositol responsive element; CHOP, C/EBP homologous protein; XBP1, X-box binding protein 1.

serve a role in immune function. A previous study revealed that cathepsin-induced ERS enhanced the recruitment of IFN regulatory factor-3 and cAMP response element binding protein $(\mathrm{CREB} / \mathrm{CBP}) / \mathrm{p} 300$ to the murine IFNB1 promoter during lipopolysaccharide stimulation. ERS-related inflammation occurred through Xbp1 binding to a potential enhancer element $6 \mathrm{~kb}$ distal to the IFNB1 gene, which may enhance the recruitment of $\mathrm{CBP} / \mathrm{p} 300$ and IFN regulatory transcription factor to the IFNB1 enhanceosome (143). This observation indicated a novel role of UPR-dependent transcription in the regulation of inflammatory cytokines, which may be of significance to the pathogenesis of diseases involving ERS and type I IFN. One potential avenue of study may be the relationship among viral infection, I/R injury and inflammatory diseases (143). ERS can activate nucleotide binding oligomerization domain-like receptor protein 1 (NLRP1) inflammatory bodies by activating the NF- $\mathrm{kB}$ signaling pathway, which may then promote myocardial I/R injury (144). NLRPs are classified as typical inflammasomes that include NLRP1 and NLRP3 inflammatory bodies. They can activate caspase-1, resulting in the maturation and secretion of pro-inflammatory cytokines IL-1 $\beta$ and IL-18 (145). How the UPR in turn mediates $\mathrm{I} / \mathrm{R}$ damage is summarized in Fig. 1B.

There are several important proteins that are activated by ERS, including ATF6, Xbp1, ATF4, CHOP and IRE1.
ATF6 normally functions in the adaptive UPR to accelerate the remodeling of cellular physiology and recovery following acute physiological and pathological injury (146). ATF6 can dimerize with UPR-regulated basic leucine zipper transcription factors, such as Xbp1, by S1P/S2P-dependent proteolysis, or associate with other stress-responsive signaling pathways such as mTOR signaling $(147,148)$. In addition, ATF6 has been reported to induce the expression of the $\mathrm{Ca}^{2+}$ pump SERCA2a and the expression of several antioxidant genes $(149,150)$.

Xbp1 has been revealed to exert protective effects against I/R injury in the heart and the brain (133,151-153), as overexpression of Xbpl can inhibit cell death induced by oxygen glucose deprivation/reoxygenation (OGD/R These findings suggested that inhibiting Xbp1 activation may accelerate neuronal cell death after $I / R$, which can be exploited as a therapeutic strategy for brain I/R injury (154). Accumulating evidence has demonstrated that ERS serves a key role in I/R-induced cell dysfunction (155), where destruction of the ER pathway can result in neuronal cell death. ERS is associated with the pathology of brain I/R injury. OGD/R stress temporarily inactivates Xbp1 splicing, resulting in accelerated neuronal death due to ER dysfunction. Subsequent Xbp1 reactivation may be neuroprotective against OGD/R stress (154).

ATF4 induces the expression of CHOP under mild ERS. However, under chronic ERS,PERK then significantly increases 
CHOP expression, in turn suppressing the expression of $\mathrm{Bcl}-2$ to increase cell death (156). In addition, PERK phosphorylates Kelch-like Ech-related protein 1, which releases Nrf2 from inhibition and translocates into the nucleus to activate the expression of antioxidant and detoxifying enzymes (157). $\mathrm{CHOP}$ has also been reported to upregulate the expression of PUMA and the pro-apoptotic protein Bim, thereby inducing mitochondrial-dependent apoptosis $(158,159)$. IRE1 is associated with autophagy activation, which is an important pro-survival defense mechanism against cardiac pathology, including hypertrophy and I/R (160).

\section{Conclusion and future perspectives}

In the present article, numerous possible causes of myocardial I/R injury, including $\mathrm{Ca}^{2+}$ overload, ROS accumulation, increase in expression of inflammatory cytokines and apoptotic factors, miRNA change and ERS were described. These factors not only lead to secondary cardiac injury but can also hinder the reconstruction of blood vessels after clinical treatment (161). Cardiac I/R injury induces changes of ERS in a process that is mainly mediated by three pathways involved in the accumulation of unfolded proteins, which causes cell damage. At the beginning of the response, a cellular protective response ensues, which then becomes apoptotic in the latter stages. However, to understand the specific mechanism underlying these processes, further study is required. Appropriate intervention in the ERS process may serve as a potential therapeutic strategy for heart I/R injury, including intervention in the expression of ligands and their receptors in the ERS pathways. With further study of cardiac ERS and I/R injury, strengthening the understanding of the mechanism underlying I/R injury will facilitate the optimization of treatment regimens. If the occurrence and development of myocardial cell apoptosis can be prevented, it may become possible to alleviate I/R injury, which will facilitate the development of treatment strategies and drug discovery for myocardial I/R.

\section{Acknowledgements}

Not applicable.

\section{Funding}

The current study was supported by grants from the National Natural Science Foundation of China (grant no. 81770292), Key Workstation Projects of He Lin (grant no. 18331101) and Wenzhou Science and Technology Major Projects (grant no. 2018ZY007).

\section{Availability of data and materials}

Not applicable.

\section{Authors' contributions}

YR and LL conceived and designed the review. YR, JZ and QJ collected the related literature. $\mathrm{MC}, \mathrm{KJ}$ and $\mathrm{ZW}$ analyzed the related papers. YR wrote the manuscript. All authors read and approved the final manuscript.

\section{Ethics approval and consent to participate}

Not applicable.

\section{Patient consent for publication}

Not applicable.

\section{Competing interests}

The authors declare that they have no competing interests.

\section{References}

1. Baulina N, Osmak G, Kiselev I, Matveeva N, Kukava N, Shakhnovich R, Kulakova O and Favorova O: NGS-identified circulating miR-375 as a potential regulating component of myocardial infarction associated network. J Mol Cell Cardiol 121: 173-179, 2018.

2. Nunez-Gomez E, Pericacho M, Ollauri-Ibanez C, Bernabeu C and Lopez-Novoa JM: The role of endoglin in post-ischemic revascularization. Angiogenesis 20: 1-24, 2017.

3. Zhou H, Ma Q, Zhu P, Ren J, Reiter RJ and Chen Y: Protective role of melatonin in cardiac ischemia-reperfusion injury: From pathogenesis to targeted therapy. J Pineal Res 64: e12471, 2018.

4. Jennings RB, Sommers HM, Smyth GA, Flack HA and Linn H: Myocardial necrosis induced by temporary occlusion of a coronary artery in the dog. Arch Pathol 70: 68-78, 1960.

5. Davidson SM, Ferdinandy P, Andreadou I, Bøtker HE, Heusch G, Ibáñez B, Ovize M, Schulz R, Yellon DM, Hausenloy DJ, et al: Multitarget strategies to reduce myocardial ischemia/reperfusion injury: JACC review topic of the week. J Am Coll Cardiol 73: 89-99, 2019.

6. Xu C, Bailly-Maitre B and Reed JC: Endoplasmic reticulum stress: Cell life and death decisions. J Clin Invest 115: 2656-2664, 2005.

7. Zhao S, Liu Y, Wang F, Xu D and Xie P: N-acetylcysteine protects against microcystin-LR-induced endoplasmic reticulum stress and germ cell apoptosis in zebrafish testes. Chemosphere 204: 463-473, 2018.

8. Liu X, Jin X, Su R and Li Z: The reproductive toxicology of male SD rats after PM2.5 exposure mediated by the stimulation of endoplasmic reticulum stress. Chemosphere 189: 547-555, 2017.

9. Almanza A, Carlesso A, Chintha C, Creedican S, Doultsinos D, Leuzzi B, Luís A, McCarthy N, Montibeller L, More S, et al: Endoplasmic reticulum stress signalling-from basic mechanisms to clinical applications. FEBS J 286: 241-278, 2019.

10. Guzel E, Arlier S, Guzeloglu-Kayisli O, Tabak MS, Ekiz T, Semerci N, Larsen K, Schatz F, Lockwood CJ and Kayisli UA: Endoplasmic reticulum stress and homeostasis in reproductive physiology and pathology. Int J Mol Sci 18: 792, 2017.

11. Xin W, Li X, Lu X, Niu K and Cai J: Involvement of endoplasmic reticulum stress-associated apoptosis in a heart failure model induced by chronic myocardial ischemia. Int J Mol Med 27: 503-509, 2011.

12. Sanada S, Komuro I and Kitakaze M: Pathophysiology of myocardial reperfusion injury: Preconditioning, postconditioning, and translational aspects of protective measures. Am J Physiol Heart Circ Physiol 301: H1723-H1741, 2011.

13. Marban E, Kitakaze M, Kusuoka H, Porterfield JK, Yue DT and Chacko VP: Intracellular free calcium concentration measured with 19F NMR spectroscopy in intact ferret hearts. Proc Natl Acad Sci USA 84: 6005-6009, 1987.

14. Kalogeris T, Baines CP, Krenz M and Korthuis RJ: Cell biology of ischemia/reperfusion injury. Int Rev Cell Mol Biol 298: 229-317, 2012.

15. Szydlowska K and Tymianski M: Calcium, ischemia and excitotoxicity. Cell Calcium 47: 122-129, 2010.

16. Jakob R, Beutner G, Sharma VK, Duan Y, Gross RA, Hurst S, Jhun BS, O-Uchi J and Sheu SS: Molecular and functional identification of a mitochondrial ryanodine receptor in neurons. Neurosci Lett 575: 7-12, 2014.

17. Peracchia C: Chemical gating of gap junction channels; roles of calcium, pH and calmodulin. Biochim Biophysica Acta 1662: 61-80, 2004. 
18. Tribulova N, Knezl V, Szeiffova Bacova B, Egan Benova T, Viczenczova C, Gonçalvesova E and Slezak J: Disordered myocardial $\mathrm{Ca}(2+)$ homeostasis results in substructural alterations that may promote occurrence of malignant arrhythmias. Physiol Res 65 (Suppl 1): S139-S148, 2016.

19. Javadov S, Hunter JC, Barreto-Torres G and Parodi-Rullan R Targeting the mitochondrial permeability transition: Cardiac ischemia-reperfusion versus carcinogenesis. Cell Physiol Biochem 27: 179-190, 2011.

20. Abdallah Y, Gkatzoflia A, Gligorievski D, Kasseckert S, Euler G Schlüter KD, Schäfer M, Piper HM and Schäfer C: Insulin protects cardiomyocytes against reoxygenation-induced hypercontracture by a survival pathway targeting $\mathrm{SR} \mathrm{Ca}^{2+}$ storage. Cardiovasc Res 70: 346-353, 2006.

21. Wu H, Yang H, Rhee JW, Zhang JZ, Lam CK, Sallam K, Chang ACY, Ma N, Lee J, Zhang $\mathrm{H}$, et al: Modelling diastolic dysfunction in induced pluripotent stem cell-derived cardiomyocytes from hypertrophic cardiomyopathy patients. Eur Heart J 40: 3685-3695, 2019.

22. Inserte J, Hernando V and Garcia-Dorado D: Contribution of calpains to myocardial ischaemia/reperfusion injury. Cardiovasc Res 96: 23-31, 2012.

23. Croall DE and Ersfeld K: The calpains: Modular designs and functional diversity. Genome Biol 8: 218, 2007.

24. Commoner B, Townsend J and Pake GE: Free radicals in biological materials. Nature 174: 689-691, 1954.

25. Cadenas S: Mitochondrial uncoupling, ROS generation and cardioprotection. Biochim Biophys Acta Bioenerg 1859: 940-950, 2018

26. Meitzler JL, Antony S, Wu Y, Juhasz A, Liu H, Jiang G, Lu J, Roy K and Doroshow JH: NADPH oxidases: A perspective on reactive oxygen species production in tumor biology. Antioxid Redox Signal 20: 2873-2889, 2014.

27. Ziech D, Franco R, Pappa A and Panayiotidis MI: Reactive oxygen species (ROS)-induced genetic and epigenetic alterations in human carcinogenesis. Mutation Res 711: 167-173, 2011.

28. Brand MD: The sites and topology of mitochondrial superoxide production. Exp Gerontol 45: 466-472, 2010.

29. Lambeth JD: NOX enzymes and the biology of reactive oxygen. Nat Rev Immunol 4: 181-189, 2004.

30. Huang P, Feng L, Oldham EA, Keating MJ and Plunkett W: Superoxide dismutase as a target for the selective killing of cancer cells. Nature 407: 390-395, 2000.

31. Srinivas US, Tan BWQ, Vellayappan BA and Jeyasekharan AD: ROS and the DNA damage response in cancer. Redox Biol 25: 101084, 2019.

32. Azevedo PS, Polegato BF, Minicucci MF, Paiva SA and Zornoff LA: Cardiac remodeling: Concepts, clinical impact, pathophysiological mechanisms and pharmacologic treatment. Arq Bras Cardiol 106: 62-69, 2016.

33. Moris D, Spartalis M, Spartalis E, Karachaliou GS, Karaolanis GI, Tsourouflis G, Tsilimigras DI, Tzatzaki E and Theocharis S: The role of reactive oxygen species in the pathophysiology of cardiovascular diseases and the clinical significance of myocardial redox. Ann Transl Med 5: 326, 2017

34. Bartz RR, Suliman HB and Piantadosi CA: Redox mechanisms of cardiomyocyte mitochondrial protection. Front Physiol 6: 291, 2015.

35. Lee HL, Chen CL, Yeh ST, Zweier JL and Chen YR: Biphasic modulation of the mitochondrial electron transport chain in myocardial ischemia and reperfusion. Am J Physiol Heart Circ Physiol 302: H1410-H1422, 2012.

36. Chen YR and Zweier JL: Cardiac mitochondria and reactive oxygen species generation. Circ Res 114: 524-537, 2014.

37. Angelova PR and Abramov AY: Functional role of mitochondrial reactive oxygen species in physiology. Free Radic Biol Med 100 81-85, 2016.

38. Chang JC, Lien CF, Lee WS, Chang HR, Hsu YC, Luo YP, Jeng JR, Hsieh JC and Yang KT: Intermittent hypoxia prevents myocardial mitochondrial $\mathrm{Ca}^{2+}$ overload and cell death during ischemia/reperfusion: The role of reactive oxygen species. Cells 8: 564, 2019.

39. Zhu WZ, Xie Y, Chen L, Yang HT and Zhou ZN: Intermittent high altitude hypoxia inhibits opening of mitochondrial permeability transition pores against reperfusion injury. J Mol Cell Cardiol 40: 96-106, 2006.

40. Aguilar M, Gonzalez-Candia A, Rodríguez J, Carrasco-Pozo C, Cañas D, García-Herrera C, Herrera EA and Castillo RL: Mechanisms of cardiovascular protection associated with intermittent hypobaric hypoxia exposure in a rat model: Role of Oxidative Stress. Int J Mol Sci 19: 366, 2018
41. Jordan JE, Zhao ZQ and Vinten-Johansen J: The role of neutrophils in myocardial ischemia-reperfusion injury. Cardiovase Res 43: 860-878, 1999.

42. Chandrasekar B, Colston JT, Geimer J, Cortez D and Freeman GL: Induction of nuclear factor kappaB but not kappaB-responsive cytokine expression during myocardial reperfusion injury after neutropenia. Free Radic Biol Med 28: 1579-1588, 2000.

43. Sugano M, Hata T, Tsuchida K, Suematsu N, Oyama J, Satoh S and Makino N: Local delivery of soluble TNF-alpha receptor 1 gene reduces infarct size following ischemia/reperfusion injury in rats. Mol Cell Biochem 266: 127-132, 2004.

44. Merchant SH, Gurule DM and Larson RS: Amelioration of ischemia-reperfusion injury with cyclic peptide blockade of ICAM-1. Am J Physiol Heart Circ Physiol 284: H1260-H1268, 2003.

45. Dar WA, Sullivan E, Bynon JS, Eltzschig H and Ju C: Ischaemia reperfusion injury in liver transplantation: Cellular and molecular mechanisms. Liver Int 39: 788-801, 2019.

46. Bhattacharya K, Farwell K, Huang M, Kempuraj D, Donelan J, Papaliodis D, Vasiadi M and Theoharides TC: Mast cell deficient W/Wv mice have lower serum IL-6 and less cardiac tissue necrosis than their normal littermates following myocardial ischemia-reperfusion. Int J Immunopathol Pharmacol 20: 69-74, 2007.

47. Yap ML and Peter K: Molecular positron emission tomography in cardiac ischemia/reperfusion. Circ Res 124: 827-829, 2019.

48. Valente $M$ and Calabrese F: Liver and apoptosis. Ital J Gastroenterol Hepatol 31: 73-77, 1999.

49. Metukuri MR, Beer-Stolz D, Namas RA, Dhupar R, Torres A, Loughran PA, Jefferson BS, Tsung A, Billiar TR, Vodovotz Y and Zamora R: Expression and subcellular localization of BNIP3 in hypoxic hepatocytes and liver stress. Am J Physiol Gastrointest Liver Physiol 296: G499-G509, 2009.

50. Wu B, Qiu W, Wang P, Yu H, Cheng T, Zambetti GP, Zhang L and Yu J: p53 independent induction of PUMA mediates intestinal apoptosis in response to ischaemia-reperfusion. Gut 56 645-654, 2007.

51. Scorrano L, Oakes SA, Opferman JT, Cheng EH, Sorcinelli MD, Pozzan T and Korsmeyer SJ: BAX and BAK regulation of endoplasmic reticulum $\mathrm{Ca}^{2+}$ : A control point for apoptosis. Science 300: 135-139, 2003

52. Kobayashi A, Imamura H, Isobe M, Matsuyama Y, Soeda J, Matsunaga K and Kawasaki S: Mac-1 (CD11b/CD18) and intercellular adhesion molecule-1 in ischemia-reperfusion injury of rat liver. Am J Physiol Gastrointest Liver Physiol 281: G577-G585, 2001.

53. Yang W, Guastella J, Huang JC, Wang Y, Zhang L, Xue D, Tran M, Woodward R, Kasibhatla S, Tseng B, et al: MX1013, a dipeptide caspase inhibitor with potent in vivo antiapoptotic activity. Br J Pharmacol 140: 402-412, 2003.

54. Vandenabeele P, Declercq W, Van Herreweghe F and Vanden Berghe T: The role of the kinases RIP1 and RIP3 in TNF-induced necrosis. Sci Signal 3: re4, 2010.

55. Kubli DA, Ycaza JE and Gustafsson AB: Bnip3 mediates mitochondrial dysfunction and cell death through Bax and Bak. Biochem J 405: 407-415, 2007.

56. Kubli DA, Quinsay MN, Huang C, Lee Y and Gustafsson AB: Bnip3 functions as a mitochondrial sensor of oxidative stress during myocardial ischemia and reperfusion. Am J Physiol Heart Circ Physiol 295: H2025-H2031, 2008.

57. Poller W, Dimmeler S, Heymans S, Zeller T, Haas J, Karakas M, Leistner DM, Jakob P, Nakagawa S, Blankenberg S, et al: Non-coding RNAs in cardiovascular diseases: Diagnostic and therapeutic perspectives. Eur Heart J 39: 2704-2716, 2018.

58. Winter J, Jung S, Keller S, Gregory RI and Diederichs S: Many roads to maturity: microRNA biogenesis pathways and their regulation. Nat Cell Biol 11: 228-234, 2009.

59. Peng L, Chun-Guang Q, Bei-Fang L, Xue-Zhi D, Zi-Hao W, Yun-Fu L, Yan-Ping D, Yang-Gui L, Wei-Guo L, Tian-Yong H and Zhen-Wen $\mathrm{H}$ : Clinical impact of circulating miR-133, miR-1291 and miR-663b in plasma of patients with acute myocardial infarction. Diagn Pathol 9: 89, 2014.

60. Zhang R, Lan C, Pei H, Duan G, Huang L and Li L: Expression of circulating miR-486 and miR-150 in patients with acute myocardial infarction. BMC Cardiovasc Disord 15: 51, 2015.

61. Joladarashi D, Garikipati VNS, Thandavarayan RA, Verma SK, Mackie AR, Khan M, Gumpert AM, Bhimaraj A, Youker KA, Uribe $\mathrm{C}$, et al: Enhanced cardiac regenerative ability of stem cells after ischemia-reperfusion injury: Role of human $\mathrm{CD} 34^{+}$ cells deficient in MicroRNA-377. J Am Coll Cardiol 66: 2214-2226, 2015 . 
62. Xu C, Lu Y, Pan Z, Chu W, Luo X, Lin H, Xiao J, Shan H, Wang Z and Yang B: The muscle-specific microRNAs miR-1 and miR-133 produce opposing effects on apoptosis by targeting HSP60, HSP70 and caspase-9 in cardiomyocytes. J Cell Sci 120: 3045-3052, 2007.

63. Tang Y, Zheng J, Sun Y, Wu Z, Liu Z and Huang G: MicroRNA-1 regulates cardiomyocyte apoptosis by targeting $\mathrm{Bcl}-2$. Int Heart J 50: 377-387, 2009.

64. Yu XY, Song YH, Geng YJ, Lin QX, Shan ZX, Lin SG and Li Y: Glucose induces apoptosis of cardiomyocytes via microRNA-1 and IGF-1. Biochem Biophys Res Commun 376: 548-552, 2008

65. Matkovich SJ, Wang W, Tu Y, Eschenbacher WH, Dorn LE, Condorelli G, Diwan A, Nerbonne JM and Dorn GW II MicroRNA-133a protects against myocardial fibrosis and modulates electrical repolarization without affecting hypertrophy in pressure-overloaded adult hearts. Circ Res 106: 166-175, 2010.

66. Cheng Y, Liu X, Zhang S, Lin Y, Yang J and Zhang C: MicroRNA-21 protects against the $\mathrm{H}(2) \mathrm{O}(2)$-induced injury on cardiac myocytes via its target gene PDCD4. J Mol Cell Cardiol 47: 5-14, 2009

67. Cheng Y, Zhu P, Yang J, Liu X, Dong S, Wang X, Chun B, Zhuang $\mathrm{J}$ and Zhang C: Ischaemic preconditioning-regulated miR-21 protects heart against ischaemia/reperfusion injury via anti-apoptosis through its target PDCD4. Cardiovas Res 87: 431-439, 2010

68. Sayed D, He M, Hong C, Gao S, Rane S, Yang Z and Abdellatif M: MicroRNA-21 is a downstream effector of AKT that mediates its antiapoptotic effects via suppression of Fas ligand. J Biol Chem 285: 20281-20290, 2010.

69. Zhu H and Fan GC: Role of microRNAs in the reperfused myocardium towards post-infarct remodelling. Cardiovasc Res 94: 284-292, 2012.

70. Magenta A, Dellambra E, Ciarapica R and Capogrossi MC: Oxidative stress, microRNAs and cytosolic calcium homeostasis. Cell Calcium 60: 207-217, 2016.

71. Cha MJ, Jang JK, Ham O, Song BW, Lee SY, Lee CY, Park JH, Lee J, Seo HH, Choi E, et al: MicroRNA-145 suppresses ROS-induced $\mathrm{Ca}^{2+}$ overload of cardiomyocytes by targeting CaMKIII. Biochem Biophys Res Commun 435: 720-726, 2013.

72. Pan L, Huang BJ, Ma XE, Wang SY, Feng J, Lv F, Liu Y, Liu Y, Li CM, Liang DD, et al: MiR-25 protects cardiomyocytes against oxidative damage by targeting the mitochondrial calcium uniporter. Int J Mol Sci 16: 5420-5433, 2015.

73. Aurora AB, Mahmoud AI, Luo X, Johnson BA, van Rooij E, Matsuzaki S, Humphries KM, Hill JA, Bassel-Duby R, Sadek HA and Olson EN: MicroRNA-214 protects the mouse heart from ischemic injury by controlling $\mathrm{Ca}^{2+}$ overload and cell death. J Clin Invest 122: 1222-1232, 2012.

74. Wang X, Zhu H, Zhang X, Liu Y, Chen J, Medvedovic M, Li H, Weiss MJ, Ren X and Fan GC: Loss of the miR-144/451 cluster impairs ischaemic preconditioning-mediated cardioprotection by targeting Rac-1. Cardiovasc Res 94: 379-390, 2012.

75. Ong SB, Katwadi K, Kwek XY, Ismail NI, Chinda K, Ong SG and Hausenloy DJ: Non-coding RNAs as therapeutic targets for preventing myocardial ischemia-reperfusion injury. Expert Opin Ther Targets 22: 247-261, 2018.

76. Ong SG and Hausenloy DJ: Hypoxia-inducible factor as a therapeutic target for cardioprotection. Pharmacol Ther 136: 69-81, 2012

77. Hinkel R, Penzkofer D, Zühlke S, Fischer A, Husada W $\mathrm{Xu} \mathrm{QF}$, Baloch E, van Rooij E, Zeiher AM, Kupatt C and Dimmeler S: Inhibition of microRNA-92a protects against ischemia/reperfusion injury in a large-animal model Circulation 128: 1066-1075, 2013.

78. Hullinger TG, Montgomery RL, Seto AG, Dickinson BA, Semus HM, Lynch JM, Dalby CM, Robinson K, Stack C, Latimer PA, et al: Inhibition of miR-15 protects against cardiac ischemic injury. Circ Res 110: 71-81, 2012.

79. Minamino T and Kitakaze M: ER stress in cardiovascular disease. J Mol Cell Cardiol 48: 1105-1110, 2010.

80. Lindholm D, Wootz H and Korhonen L: ER stress and neurodegenerative diseases. Cell Death Differ 13: 385-392, 2006.

81. Matus S, Glimcher LH and Hetz C: Protein folding stress in neurodegenerative diseases: A glimpse into the ER. Curr Opin Cell Biol 23: 239-252, 2011.

82. Hotamisligil GS: Endoplasmic reticulum stress and the inflammatory basis of metabolic disease. Cell 140: 900-917, 2010.

83. Chiang CK, Hsu SP, Wu CT, Huang JW, Cheng HT, Chang YW, Hung KY, Wu KD and Liu SH: Endoplasmic reticulum stress implicated in the development of renal fibrosis. Mol Med 17: $1295-1305,2011$.
84. Zhang L, Wang Y, Zhang L, Xia X, Chao Y, He R, Han C and Zhao W: ZBTB7A, a miR-663a target gene, protects osteosarcoma from endoplasmic reticulum stress-induced apoptosis by suppressing LncRNA GAS5 expression. Cancer Lett 448: 105-116, 2019.

85. Wang EM, Akasaka H, Zhao J, Varadhachary GR, Lee JE, Maitra A, Fleming JB, Hung MC, Wang H and Katz MH: Expression and clinical significance of protein kinase RNA-like endoplasmic reticulum kinase and phosphorylated eukaryotic initiation factor $2 \alpha$ in pancreatic ductal adenocarcinoma. Pancreas 48: 323-328, 2019.

86. Yu LM, Dong X, Zhang J, Li Z, Xue XD, Wu HJ, Yang ZL, Yang Y and Wang HS: Naringenin attenuates myocardial ischemia-reperfusion injury via cGMP-PKGI $\alpha$ signaling and in vivo and in vitro studies. Oxid Med Cell Longev 2019: 7670854, 2019.

87. Peñaranda Fajardo NM, Meijer C and Kruyt FA: The endoplasmic reticulum stress/unfolded protein response in gliomagenesis, tumor progression and as a therapeutic target in glioblastoma. Biochem Pharmacol 118: 1-8, 2016.

88. Beck D, Niessner H, Smalley KS, Flaherty K, Paraiso KH, Busch C, Sinnberg T, Vasseur S, Iovanna JL, Drießen S, et al: Vemurafenib potently induces endoplasmic reticulum stress-mediated apoptosis in BRAFV600E melanoma cells. Sci Signal 6: ra7, 2013.

89. Lee JH, Kwon EJ and Kim DH: Calumenin has a role in the alleviation of ER stress in neonatal rat cardiomyocytes. Biochem Biophys Res Commun 439: 327-332, 2013.

90. Brewer JW and Diehl JA: PERK mediates cell-cycle exit during the mammalian unfolded protein response. Proc Natl Acad Sci USA 97: 12625-12630, 2000.

91. Zhang M, Han N, Jiang Y, Wang J, Li G, Lv X, Li G and Qiao Q: EGFR confers radioresistance in human oropharyngeal carcinoma by activating endoplasmic reticulum stress signaling PERK-eIF2 $\alpha$-GRP94 and IRE1 $\alpha$-XBP1-GRP78. Cancer Med 7: 6234-6246, 2018.

92. Oyadomari S and Mori M: Roles of CHOP/GADD153 in endoplasmic reticulum stress. Cell Death Differ 11: 381-389, 2004.

93. Palam LR, Baird TD and Wek RC: Phosphorylation of eIF2 facilitates ribosomal bypass of an inhibitory upstream ORF to enhance CHOP translation. J Biol Chem 286: 10939-10949, 2011.

94. Oyadomari S, Koizumi A, Takeda K, Gotoh T, Akira S, Araki E and Mori M: Targeted disruption of the Chop gene delays endoplasmic reticulum stress-mediated diabetes. J Clin Invest 109: 525-532, 2002

95. Yao Y, Lu Q, Hu Z, Yu Y, Chen Q and Wang QK: A non-canonical pathway regulates ER stress signaling and blocks ER stress-induced apoptosis and heart failure. Nat Commun 8: 133, 2017.

96. Correll RN, Grimes KM, Prasad V, Lynch JM, Khalil H and Molkentin JD: Overlapping and differential functions of ATF6a versus ATF6 $\beta$ in the mouse heart. Sci Rep 9: 2059, 2019.

97. Okada T, Yoshida H, Akazawa R, Negishi M and Mori K Distinct roles of activating transcription factor 6 (ATF6) and double-stranded RNA-activated protein kinase-like endoplasmic reticulum kinase (PERK) in transcription during the mammalian unfolded protein response. Biochem J 366: 585-594, 2002.

98. Yoshida H, Okada T, Haze K, Yanagi H, Yura T, Negishi M and Mori K: ATF6 activated by proteolysis binds in the presence of NF-Y (CBF) directly to the cis-acting element responsible for the mammalian unfolded protein response. Mol Cell Biol 20: 6755-6767, 2000.

99. Xiang C, Wang Y, Zhang H and Han F: The role of endoplasmic reticulum stress in neurodegenerative disease. Apoptosis 22: $1-26,2017$.

100. Korennykh A and Walter P: Structural basis of the unfolded protein response. Annu Rev Cell Dev Biol 28: 251-277, 2012

101. Tsuru A, Fujimoto N, Takahashi S, Saito M, Nakamura D, Iwano M, Iwawaki T, Kadokura H, Ron D and Kohno K: Negative feedback by IRE1 $\beta$ optimizes mucin production in goblet cells. Proc Natl Acad Sci USA 110: 2864-2869, 2013.

102. Pavitt GD and Ron D: New insights into translational regulation in the endoplasmic reticulum unfolded protein response. Cold Spring Harbor Perspect Biol 4: a012278, 2012.

103. Han F, Yan S and Shi Y: Single-prolonged stress induces endoplasmic reticulum-dependent apoptosis in the hippocampus in a rat model of Post-traumatic stress disorder. PLoS One 8: e69340, 2013

104. Yu B, Wen L, Xiao B, Han F and Shi Y: Single prolonged stress induces ATF6 alpha-dependent Endoplasmic reticulum stress and the apoptotic process in medial Frontal Cortex neurons. BMC Neurosci 15: 115, 2014. 
105. Walter P and Ron D: The unfolded protein response: From stress pathway to homeostatic regulation. Science 334: 1081-1086, 2011.

106. Maly DJ and Papa FR: Druggable sensors of the unfolded protein response. Nat Chem Biol 10: 892-901, 2014.

107. Yoshida H: ER stress and diseases. FEBS J 274: 630-658, 2007.

108. Paschen W: Endoplasmic reticulum dysfunction in brain pathology: Critical role of protein synthesis. Curr Neurovasc Res 1: 173-181, 2004.

109. Thuerauf DJ, Marcinko M, Gude N, Rubio M, Sussman MA and Glembotski CC: Activation of the unfolded protein response in infarcted mouse heart and hypoxic cultured cardiac myocytes. Circ Res 99: 275-282, 2006.

110. Severino A, Campioni M, Straino S, Salloum FN, Schmidt N, Herbrand U, Frede S, Toietta G, Di Rocco G, Bussani R, et al: Identification of protein disulfide isomerase as a cardiomyocyte survival factor in ischemic cardiomyopathy. J Am Coll Cardiol 50: 1029-1037, 2007.

111. Terai K, Hiramoto Y, Masaki M, Sugiyama S, Kuroda T, Hori M, Kawase I and Hirota H: AMP-activated protein kinase protects cardiomyocytes against hypoxic injury through attenuation of endoplasmic reticulum stress. Mol Cell Biol 25: 9554-9575, 2005.

112. Glembotski CC: The role of the unfolded protein response in the heart. J Mol Cell Cardiol 44: 453-459, 2008

113. Hadley G, Neuhaus AA, Couch Y, Beard DJ, Adriaanse BA, Vekrellis K, DeLuca GC, Papadakis M, Sutherland BA and Buchan AM: The role of the endoplasmic reticulum stress response following cerebral ischemia. Int J Stroke 13: 379-390, 2018.

114. Lehotský J, Urban P, Pavlíková M, Tatarková Z, Kaminska B and Lehotský J: Molecular mechanisms leading to neuroprotection/ischemic tolerance: Effect of preconditioning on the stress reaction of endoplasmic reticulum. Cell Mol Neurobiol 29: 917-925, 2009.

115. Eijkelenboom A and Burgering BM: FOXOs: Signalling integrators for homeostasis maintenance. Nat Rev Mol Cell Biol 14 83-97, 2013.

116. Huang $\mathrm{H}$ and Tindall DJ: Dynamic FoxO transcription factors J Cell Sci 120: 2479-2487, 2007.

117. Chien CT, Lee PH, Chen CF, Ma MC, Lai MK and Hsu SM De novo demonstration and co-localization of free-radical production and apoptosis formation in rat kidney subjected to ischemia/reperfusion. J Am Soc Nephrol 12: 973-982, 2001

118. Liu H, Wang L, Weng X, Chen H, Du Y, Diao C, Chen Z and Liu X: Inhibition of Brd4 alleviates renal ischemia/reperfusion injury-induced apoptosis and endoplasmic reticulum stress by blocking FoxO4-mediated oxidative stress. Redox Biol 24 101195, 2019.

119. Ren L, Wang Q, Chen Y, Ma Y and Wang D: Involvement of MicroRNA-133a in the protective effect of hydrogen sulfide against ischemia/Reperfusion-induced endoplasmic reticulum stress and cardiomyocyte apoptosis. Pharmacology 103: 1-9, 2019.

120. Yan Y, Zhang B, Liu N, Qi C, Xiao Y, Tian X, Li T and Liu B Circulating long noncoding RNA UCA1 as a novel biomarker of acute myocardial infarction. BioMed Res Int 2016: 8079372, 2016

121. Chen J, Hu Q, Zhang BF, Liu XP, Yang S and Jiang H: Long noncoding RNA UCA1 inhibits ischaemia/reperfusion injury induced cardiomyocytes apoptosis via suppression of endoplasmic reticulum stress. Genes Genomics 41: 803-810, 2019.

122. Guo R, Ma H, Gao F, Zhong L and Ren J: Metallothionein alleviates oxidative stress-induced endoplasmic reticulum stress and myocardial dysfunction. J Mol Cell Cardiol 47: 228-237, 2009.

123. Minamino T, Komuro I and Kitakaze M: Endoplasmic reticulum stress as a therapeutic target in cardiovascular disease. Circ Res 107: 1071-1082, 2010.

124. Glembotski CC: Endoplasmic reticulum stress in the heart. Circ Res 101: 975-984, 2007.

125. Urano F, Wang X, Bertolotti A, Zhang Y, Chung P, Harding HP and Ron D: Coupling of stress in the ER to activation of JNK protein kinases by transmembrane protein kinase IRE1. Science 287: 664-666, 2000

126. Yoneda T, Imaizumi K, Oono K, Yui D, Gomi F, Katayama T and Tohyama M: Activation of caspase-12, an endoplastic reticulum (ER) resident caspase, through tumor necrosis factor receptor-associated factor 2-dependent mechanism in response to the ER stress. J Biol Chem 276: 13935-13940, 2001.

127. Martindale JJ, Fernandez R, Thuerauf D, Whittaker R, Gude N, Sussman MA and Glembotski CC: Endoplasmic reticulum stress gene induction and protection from ischemia/reperfusion injury in the hearts of transgenic mice with a tamoxifen-regulated form of ATF6. Circ Res 98: 1186-1193, 2006.
128. Shintani-Ishida K, Nakajima M, Uemura K and Yoshida K Ischemic preconditioning protects cardiomyocytes against ischemic injury by inducing GRP78. Biochem Biophys Res Commun 345: 1600-1605, 2006

129. Weigand K, Brost S, Steinebrunner N, Buchler M, Schemmer P and Muller M: Ischemia/Reperfusion injury in liver surgery and transplantation: Pathophysiology. HPB Surg 2012: 176723, 2012.

130. Hartley T, Siva M, Lai E, Teodoro T, Zhang L and Volchuk A: Endoplasmic reticulum stress response in an INS-1 pancreatic beta-cell line with inducible expression of a folding-deficient proinsulin. BMC Cell Biol 11: 59, 2010.

131. Szegezdi E, Duffy A, O'Mahoney ME, Logue SE, Mylotte LA, O'brien T and Samali A: ER stress contributes to ischemia-induced cardiomyocyte apoptosis. Biochem Biophys Res Commun 349: 1406-1411, 2006.

132. Murphy E and Steenbergen C: Mechanisms underlying acute protection from cardiac ischemia-reperfusion injury. Physiol Rev 88: 581-609, 2008.

133. Wang X, Xu L, Gillette TG, Jiang X and Wang ZV: The unfolded protein response in ischemic heart disease. J Mol Cell Cardiol 117: 19-25, 2018.

134. Yang W and Paschen W: Unfolded protein response in brain ischemia: A timely update. J Cereb Blood Flow Metab 36: 2044-2050, 2016

135. Tabas I and Ron D: Integrating the mechanisms of apoptosis induced by endoplasmic reticulum stress. Nat Cell Biol 13: 184-190, 2011.

136. Li G, Mongillo M, Chin KT, Harding H, Ron D, Marks AR and Tabas I: Role of ERO1-alpha-mediated stimulation of inositol 1,4,5-triphosphate receptor activity in endoplasmic reticulum stress-induced apoptosis. J Cell Biol 186: 783-792, 2009.

137. Timmins JM, Ozcan L, Seimon TA, Li G, Malagelada C, Backs J, Backs T, Bassel-Duby R, Olson EN, Anderson ME and Tabas I: Calcium/calmodulin-dependent protein kinase II links ER stress with Fas and mitochondrial apoptosis pathways. J Clin Invest 119: 2925-2941, 2009.

138. Vitadello M, Penzo D, Petronilli V, Michieli G, Gomirato S, Menabò R, Di Lisa F and Gorza L: Overexpression of the stress protein Grp94 reduces cardiomyocyte necrosis due to calcium overload and simulated ischemia. FASEB J 17: 923-925, 2003

139. Ikeda Y, Young LH and Lefer AM: Attenuation of neutrophilmediated myocardial ischemia-reperfusion injury by a calpain inhibitor. Am J Physiol Heart Circ Physiol 282: H1421-H1426, 2002.

140. Hernando V, Inserte J, Sartorio CL, Parra VM, Poncelas-Nozal M and Garcia-Dorado D: Calpain translocation and activation as pharmacological targets during myocardial ischemia/ reperfusion. J Mol Cell Cardiol 49: 271-279, 2010.

141. Zheng D, Wang G, Li S, Fan GC and Peng T: Calpain-1 induces endoplasmic reticulum stress in promoting cardiomyocyte apoptosis following hypoxia/reoxygenation. Biochim Biophys Acta 1852: 882-892, 2015.

142. Munoz JP,IvanovaS, Sanchez-Wandelmer J,Martínez-CristóbalP, Noguera E, Sancho A, Díaz-Ramos A, Hernández-Alvarez MI, Sebastián D, Mauvezin C, et al: Mfn2 modulates the UPR and mitochondrial function via repression of PERK. EMBO J 32: 2348-2361, 2013.

143. Zeng L, Liu YP, Sha H, Chen H, Qi L and Smith JA: XBP-1 couples endoplasmic reticulum stress to augmented IFN-beta induction via a cis-acting enhancer in macrophages. J Immunol 185: 2324-2330, 2010.

144. Cao L, Chen Y, Zhang Z, Li Y and Zhao P: Endoplasmic reticulum stress-induced NLRP1 inflammasome activation contributes to myocardial ischemia/reperfusion injury. Shock 51: 511-518, 2019.

145. Yi YS: Role of inflammasomes in inflammatory autoimmune rheumatic diseases. Korean J Physiol Pharmacol 22: 1-15, 2018.

146. Zhang G, Wang X, Gillette TG, Deng Y and Wang ZV: Unfolded protein response as a therapeutic target in cardiovascular disease. Curr Top Med Chem 19: 1902-1917, 2019.

147. Asada R, Kanemoto S, Kondo S, Saito A and Imaizumi K The signalling from endoplasmic reticulum-resident bZIP transcription factors involved in diverse cellular physiology. J Biochem 149: 507-518, 2011.

148. Zhang K, Shen X, Wu J, Sakaki K, Saunders T, Rutkowski DT, Back SH and Kaufman RJ: Endoplasmic reticulum stress activates cleavage of CREBH to induce a systemic inflammatory response. Cell 124: 587-599, 2006. 
149. Jin JK, Blackwood EA, Azizi K, Thuerauf DJ, Fahem AG, Hofmann C, Kaufman RJ, Doroudgar S and Glembotski CC: ATF6 decreases myocardial ischemia/reperfusion damage and links ER stress and oxidative stress signaling pathways in the heart. Circ Res 120: 862-875, 2017.

150. Thuerauf DJ, Hoover H, Meller J, Hernandez J, Su L, Andrews C, Dillmann WH, McDonough PM and Glembotski CC: Sarco/endoplasmic reticulum calcium ATPase-2 expression is regulated by ATF6 during the endoplasmic reticulum stress response: Intracellular signaling of calcium stress in a cardiac myocyte model system. J Biol Chem 276: 48309-48317, 2001.

151. Zhang C, Tang Y, Li Y, Xie L, Zhuang W, Liu J and Gong J: Unfolded protein response plays a critical role in heart damage after myocardial ischemia/reperfusion in rats. PLoS One 12 e0179042, 2017.

152. Jiang D, Niwa M and Koong AC: Targeting the IRE1 $\alpha-X B P 1$ branch of the unfolded protein response in human diseases. Semin Cancer Biol 33: 48-56, 2015

153. Schmitz ML, Shaban MS, Albert BV, Gökçen A and Kracht M: The crosstalk of endoplasmic reticulum (ER) stress pathways with NF- $\kappa \mathrm{B}$ : Complex mechanisms relevant for cancer, inflammation and infection. Biomedicines 6: 58, 2018.

154. Ibuki T, Yamasaki Y, Mizuguchi H and Sokabe M: Protective effects of XBP1 against oxygen and glucose deprivation/reoxygenation injury in rat primary hippocampal neurons. Neurosci Lett 518: 45-48, 2012.

155. DeGracia DJ and Montie HL: Cerebral ischemia and the unfolded protein response. J Neurochem 91: 1-8, 2004.
156. McCullough KD, Martindale JL, Klotz LO, Aw TY and Holbrook NJ: Gadd153 sensitizes cells to endoplasmic reticulum stress by down-regulating $\mathrm{Bcl} 2$ and perturbing the cellular redox state. Mol Cell Biol 21: 1249-1259, 2001.

157. Cullinan SB, Zhang D, Hannink M, Arvisais E, Kaufman RJ and Diehl JA: Nrf2 is a direct PERK substrate and effector of PERK-dependent cell survival. Mol Cell Biol 23: 7198-7209, 2003.

158. Puthalakath H, O'Reilly LA, Gunn P, Lee L, Kelly PN, Huntington ND,HughesPD,MichalakEM,McKimm-BreschkinJ, Motoyama N, et al: ER stress triggers apoptosis by activating BH3-only protein Bim. Cell 129: 1337-1349, 2007.

159. Ghosh AP, Klocke BJ, Ballestas ME and Roth KA: CHOP potentially co-operates with FOXO3a in neuronal cells to regulate PUMA and BIM expression in response to ER stress. PLoS One 7: e39586, 2012.

160. De Meyer GR and Martinet W: Autophagy in the cardiovascular system. Biochim Biophy Acta 1793: 1485-1495, 2009.

161. Wei L, Zhang Y, Qi X, Sun X, Li Y and Xu Y: Ubiquitinproteasomes are the dominant mediators of the regulatory effect of microRNA-1 on cardiac remodeling after myocardial infarction. Int J Mol Med 44: 1899-1907, 2019.

cc) (i) $(-)$ This work is licensed under a Creative Commons International (CC BY-NC-ND 4.0) License. 